\title{
Mesenteric artery syndrome associated with HAART onset in a patient with HIV
}

\author{
Jorge Humberto Rodríguez-Quintero, Oscar Santes, Jesus Morales-Maza
}

General Surgery, Instituto Nacional de Ciencias Medicas y Nutricion Salvador Zubiran, Mexico City, Mexico

\section{Correspondence to}

Dr Jorge Humberto RodríguezQuintero, huroqu90@gmail.com

Accepted 14 February 2018

\section{DESCRIPTION}

A 28-year-old man (body mass index (BMI) of $15.6 \mathrm{~kg} / \mathrm{m}^{2}$ ) with untreated HIV infection since 2004 was admitted to the hospital with a 3-month headache, generalised weakness and neurocognitive deficit. He underwent head MRI and a ring-enhancing lesion was found in subcortical temporal-occipital location. Cerebral biopsy revealed primary central nervous system lymphoma. The patient received chemotherapy with cytarabine, rituximab and high-dose methotrexate without complications. Simultaneously, he was started on antiretroviral therapy (ritonavir, darunavir, raltegravir and tenofovir). Two weeks after highly active antiretroviral therapy (HAART) onset, he developed sudden abdominal pain, distention and profuse biliary vomit. CT angiography revealed severe dilation of the stomach and duodenum until its third portion with a transition zone at the level of the superior mesenteric artery (SMA) (figure 1).

An aortomesenteric angle of $13^{\circ}$ and a distance of $5 \mathrm{~mm}$ between the aorta and SMA were measured with evident compression of the duodenum between such structures noticed. Initially, a nasogastric catheter was placed in order to relieve the obstruction and total parenteral nutrition was started. Two days later, he underwent upper endoscopy and a nasojejunal catheter was advanced to start enteral nutrition. While on enteral nutrition we observed gradual weight increase, and after reaching BMI of
16.8 he was able to start a soft diet with posterior removal of the catheter (figures 2 and 3).

Superior mesenteric artery syndrome (SMAS) is a condition characterised by an acute or chronic compression of the third portion of the duodenum between the aorta posteriorly and the SMA anteriorly.

Anatomically, it can be explained by the dual embryologic origin of the duodenum and its vascular supply; it is a very unusual disease, its incidence in radiological studies has been described between $0.20 \%$ and $0.78 \%{ }^{1}$

It has classically been associated to specific conditions such as abrupt weight loss, prolonged bed rest, spinal deformities and several catabolic states. $^{2}$ Studies suggest there may be contribution of anatomical factors such as a short mesentery, an altered anatomy or an abnormally high fixation by the ligament of Treitz for its development.

It has been seldom reported in patients with HIV, and never before in association with HAART onset; this is relevant regarding the well-known effects HAART has on lipid metabolism which are suspected to be dependent on a similarity of an HIV-1 protease and two homologous human proteins (CRABP-1 and LRP1).

About the diagnostic approach, SMAS must be suspected in all patients presenting with symptoms of high intestinal obstruction such as biliary vomit, epigastric pain and oral intolerance. Differential

\section{Check for updates}

\section{To cite:}

Rodríguez-Quintero JH, Santes 0, Morales-Maza J. BMJ Case Rep Published Online First: [please include Day Month Year]. doi:10.1136/bcr-2018224214

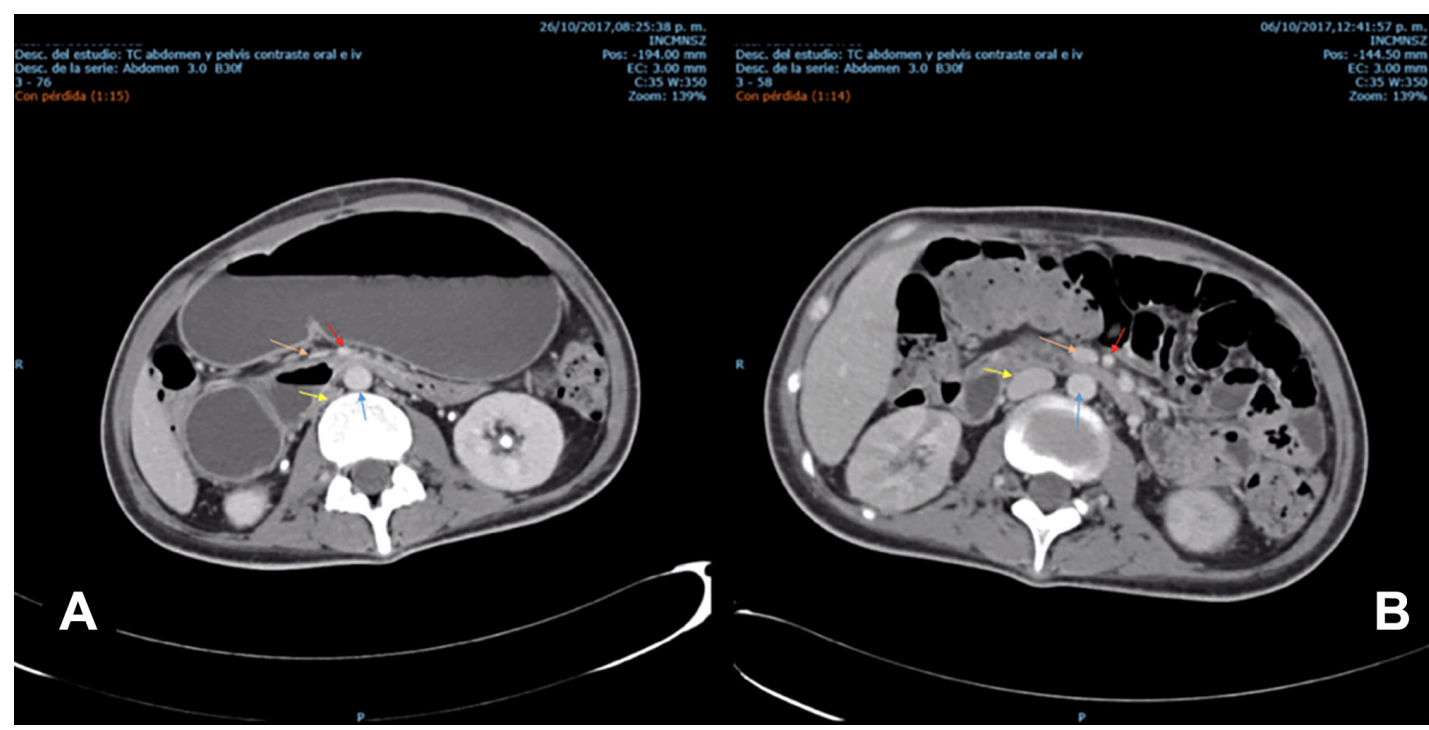

Figure 1 (A) Axial CT images show compression of the third portion of the duodenum between aorta (blue) and superior mesenteric artery (SMA) (red). Also, dilation of the stomach and proximal duodenum with a collapsed superior mesenteric vein (SMV) (orange) and vena cava (yellow). (B) CT scan taken 20 days before showing the same structures on their original distribution. 


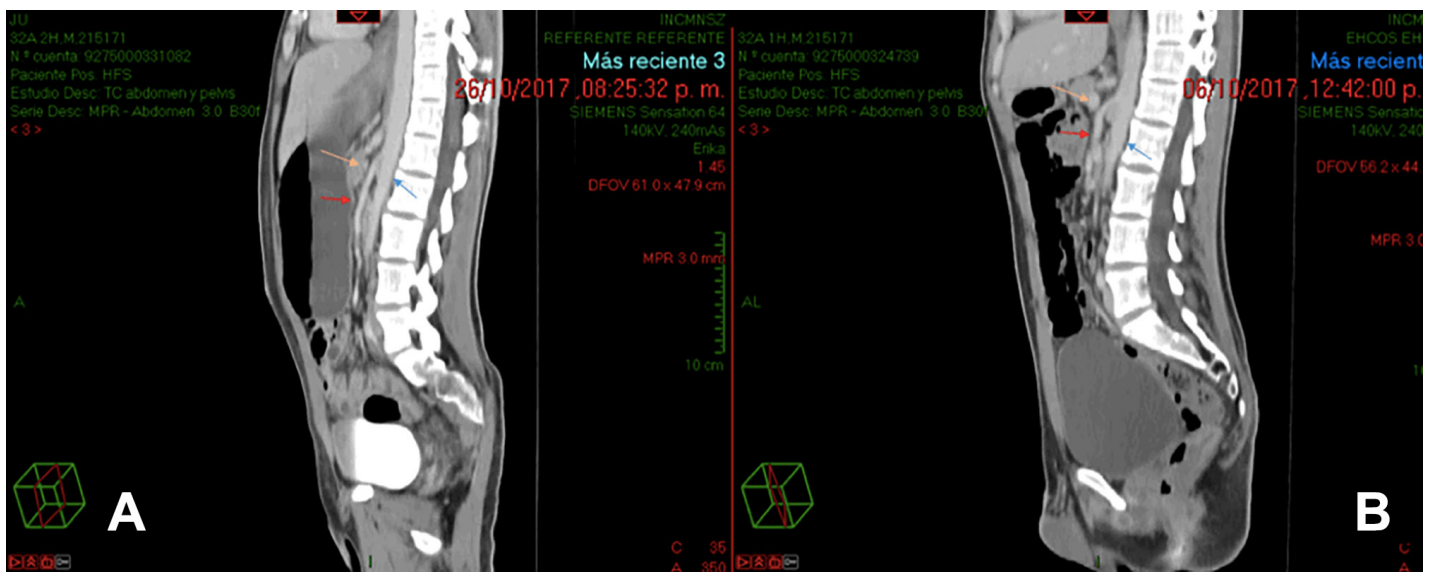

Figure 2 (A) Sagittal plane showing acute aorto (blue)-mesenteric (red) angulation and compression of the superior mesenteric vein (SMV) (orange). (B) CT scan 20 days before showing a wider angle and normal SMV.

diagnosis must include internal hernias, intestinal adherences, pyloric stenosis, acute gastritis and acute/chronic pancreatitis. Laboratory tests must be directed to identifying complications as intestinal ischaemia or perforation, with at least C-reactive protein, complete blood count, blood chemistry and lactate

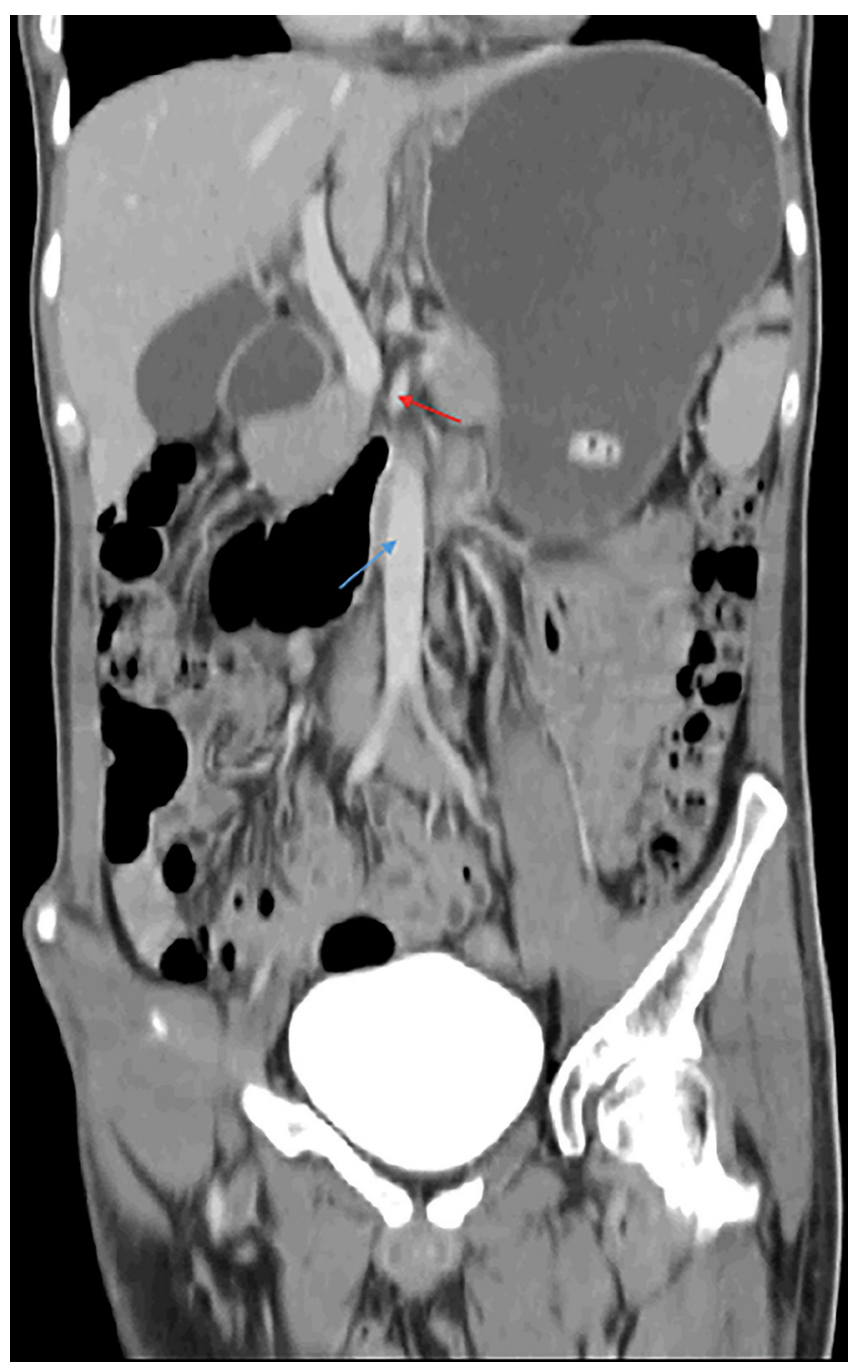

Figure 3 Coronal plane showing superior mesenteric artery (SMA) (red) and aorta (blue) with transition zone in between. levels. Plain radiographs usually show non-specific gastrointestinal dilation, whereas barium studies may add signs of linear extrinsic pressure at the occlusion site. The most effective study is CT, which can measure the distance and angulation between aorta and SMA, as well as give an estimate of retroperitoneal fat status and identify abdominal complications. Studies have shown that aortomesenteric angles of $8^{\circ}-10^{\circ}$ and distances of $5.7-11 \mathrm{~mm}$ are highly suggestive of this syndrome. ${ }^{3}$

In our case, we believe both antiretrovirals and chemotherapy may have contributed to depletion of the lipid reserve of the body, leading to a reduced retroperitoneal fat pad and SMAS. Fortunately, we had obtained a previous CT scan which helped us characterise structural before/after changes associated with this condition.

Currently, there are no concise guidelines on treatment. However, experience has shown us it requires early surgical team involvement to avoid poor outcomes. In general terms, primary management consists of NPO (nil per os), gastric decompression and starting early caloric supply, reserving operative approaches to cases that fail such measures. Duodenal mobilisation (Strong's technique) is considered the standard surgical procedure whereas minimally invasive approaches have recently shown promising outcomes. Conservative treatment success will be strictly associated with prompt caloric supply and weight recovery.

\section{Learning points}

- Superior mesenteric artery syndrome is caused by compression of the third portion of the duodenum between the superior mesenteric artery and the aorta.

- It must be considered in the differential diagnosis of patients presenting with symptoms of high bowel obstruction.

- Strong association with catabolic states and depleted lipid reserve is suspected in patients receiving highly active antiretroviral therapy or chemotherapy.

Contributors JHRQ was responsible for planning of the case and conceived the original idea. JHRQ, OS and JMM wrote the manuscript. OS helped supervise and conduct the project. The design of the manuscript was done by JHRQ and OS. Aquiring of data was achieved by JMM and aquiring and preparing of the images was done by JHRQ and OS. The interpretation of data was performed by JHRQ, OS and JMM.

Funding This research received no specific grant from any funding agency in the public, commercial or not-for-profit sectors. 
Competing interests None declared.

\section{Patient consent Obtained.}

Provenance and peer review Not commissioned; externally peer reviewed.

(C) BMJ Publishing Group Ltd (unless otherwise stated in the text of the article) 2018. All rights reserved. No commercial use is permitted unless otherwise expressly granted.

\section{REFERENCES}

1 Mathenge N, Osiro S, Rodriguez II, et al. Superior mesenteric artery syndrome and its associated gastrointestinal implications. Clinical Anatomy 2014:27:1244-52.

2 Hoffman RJ, Arpadi SM. Case report: a pediatric AIDS patient with superior mesenteric artery syndrome. AIDS Patient Care STDS 2000;14:3-6.

3 Konen $\mathrm{E}$, Amitai $\mathrm{M}$, Apter $\mathrm{S}$, et al. CT angiography of superior mesenteric artery syndrome. AJR Am J Roentgenol 1998;171:1279-81.

Copyright 2018 BMJ Publishing Group. All rights reserved. For permission to reuse any of this content visit http://group.bmj.com/group/rights-licensing/permissions.

BMJ Case Report Fellows may re-use this article for personal use and teaching without any further permission.

Become a Fellow of BMJ Case Reports today and you can:

- Submit as many cases as you like

- Enjoy fast sympathetic peer review and rapid publication of accepted articles

- Access all the published articles

Re-use any of the published material for personal use and teaching without further permission

For information on Institutional Fellowships contact consortiasales@bmjgroup.com

Visit casereports.bmj.com for more articles like this and to become a Fellow 